\title{
Como realizamos o processamento de endoscópios flexíveis - Relato de experiência
}

\author{
How we process flexible endloscopes - Experience report \\ Cómo realizamos el procesamiento de endoscopios flexibles - Informe de experiencia
}

ORCID: https://orcid.org/0000-0002-0398-6595 Hospital de Clínicas de Porto Alegre, Brasil

E-mail: orubin@hcpa.edu.br

Rosaura Soares Paczek

ORCID: https://orcid.org/0000-0002-4397-1814 Hospital de Clínicas de Porto Alegre, Brasil

E-mail: rspaczek@gmail.com

Bruna Noschang Brum

ORCID: https://orcid.org/0000-0003-0902-0449

Universidade Federal do Rio Grande do Sul, Brasil E-mail: brunanoschang1@gmail.com

Lisiane Paula Sordi Matzenbacher

ORCID: https://orcid.org/0000-0002-1407-7717 Hospital de Clínicas de Porto Alegre, Brasil E-mail: 1sordi@hcpa.edu.br

Ana Karina Silva da Rocha Tanaka

ORCID: https://orcid.org/0000-0003-2488-3656

Universidade Federal do Rio Grande do Sul, Brasil E-mail: anakarinatanaka@gmail.com

Ana Maria Pagliarini

ORCID: https://orcid.org/0000-0003-4585-4846 Universidade Federal do Rio Grande do Sul, Brasil E-mail: apagliarini@hcpa.edu.br

Débora Machado Nascimento do Espírito Santo

ORCID: https://orcid.org/0000-0003-0533-0335 Hospital de Clínicas de Porto Alegre, Brasil E-mail: dsanto@hcpa.edu.br

Carina Galvan

ORCID: https://orcid.org/0000-0003-2111-5432 Hospital de Clínicas de Porto Alegre, Brasil E-mail: cgalvan@hcpa.edu.br

\begin{abstract}
Resumo
Objetivo: relatar como realizamos o processo de limpeza de endoscópios flexíveis. Método: estudo descritivo, tipo relato de experiência, sobre o processo de limpeza e desinfecção de endoscópios flexíveis em um hospital universitário do sul do Brasil. Resultados: após a utilização do endoscópio flexível, iniciar o teste de vazamento na sala de exame logo após o término do procedimento, juntamente com a pré-limpeza do dispositivo em cuba com solução de detergente enzimático diluído. A inspeção visual deve ser realizada antes da realização da desinfecção de alto nível, de acordo com sua classificação como acessório crítico, utilizado em procedimentos invasivos com penetração da pele, mucosas, espaços ou cavidades estéreis, tecidos subepiteliais e sistema vascular. Após a limpeza manual, o processo de limpeza automatizado é realizado, incluindo enxágue e desinfecção de alto nível. Em seguida, o dispositivo é identificado no processamento realizado e armazenado em armários na posição vertical. Conclusão: o reprocessamento de endoscópios flexíveis deve seguir recomendações baseadas em evidências em diretrizes atualizadas, investimento na estrutura física com fluxos corretos e armazenamento dos equipamentos de forma adequada à realidade do serviço para reduzir o índice de infecção.

Palavras-chave: Desinfecção; Endoscopia; Serviço hospitalar de enfermagem; Enfermagem; Contaminação de equipamentos.

\footnotetext{
Abstract

Objective: to report on how we carry out the cleaning process of flexible endoscopes. Method: a descriptive study, experience report type, about the cleaning and disinfection process of flexible endoscopes in a teaching hospital in southern Brazil. Results: after using the flexible endoscope, start the leak test in the examination room right after the end of the procedure, together with a pre-cleaning of the device in a vat of diluted enzymatic detergent solution. Visual inspection should be performed prior to performing high-level disinfection, according to its classification as a
} 
critical accessory, used in invasive procedures with penetration of the skin, mucous membranes, sterile spaces or cavities, sub-epithelial tissues and vascular system. After manual cleaning, the automated cleaning process is performed, including rinsing and high-level disinfection. Then the device is identified on the processing carried out and stored in cabinets in the vertical position. Conclusion: the reprocessing of flexible endoscopes must follow recommendations based on evidence in updated guidelines, investment in the physical structure with correct flows and storage of equipment in a manner appropriate to the reality of the service to reduce the rate of infection.

Keywords: Disinfection; Endoscopy; Hospital nursing servisse; Nursing; Equipment contamination.

\section{Resumen}

Objetivo: relatar sobre cómo realizamos el proceso de limpieza de endoscopios flexibles. Método: estudio descriptivo, tipo relato de experiencia sobre el proceso de limpieza y desinfección de endoscopios flexibles en un hospital universitario del sur de Brasil. Resultados: después de utilizar el endoscopio flexible, se inicia la prueba de fugas en la sala de exámen, después de finalizado el procedimiento, juntamente con una limpieza previa del dispositivo en una tina con una solución de detergente enzimático diluido. La inspección visual debe realizarse antes de realizar una desinfección de alto nivel, según su clasificación como accesorio crítico, utilizado en un procedimiento invasivo con penetración de la piel, mucosas, espacios o cavidades estériles, tejidos subepiteliales y sistema vascular. Después de la limpieza manual, se lleva a cabo el proceso de limpieza automatizado, que incluye un enjuague y desinfección de alto nivel. Luego, el dispositivo se identifica en el procesamiento realizado y se almacena en armarios en posición vertical. Conclusión: el reprocesamiento de endoscopios flexibles debe seguir recomendaciones basadas en evidencia en las guías actualizadas, inversión en estructura física con flujos correctos y almacenamiento de equipos de manera adecuada a la realidad del servicio para reducir la tasa de infección.

Palabras clave: Desinfección; Endoscopia; Servicio de enfermería hospitalaria; Enfermería; Contaminación de los equipamentos.

\section{Introdução}

A palavra endoscopia origina-se do grego, significa olhar dentro, sendo examinadas as cavidades do corpo, realizada por endoscópios rígidos ou flexíveis. O primeiro endoscópio foi utilizado na Alemanha em 1806, usando espelhos côncavos para examinar a bexiga. Em 1860, foi realizada a primeira esofagograstroscopia com ajuda de engolidor de espadas. A partir de 1930, surgiram os endoscópios flexíveis, que avançaram para endoscópios de fibra óptica, melhorando a qualidade dos exames com imagens de alta definição (Schwab \& Singh, 2011).

A endoscopia digestiva é realizada para diagnóstico e tratamento de várias doenças gastrointestinais, através de equipamentos de alta tecnologia e custo elevado, compostos por longos canais, com design complexo, produzidos com material de fibra óptica, sendo difíceis de limpar e fáceis de danificar (Oliveira \& Mati, 2015; Ribeiro et al., 2013).

Os aparelhos são expostos a vários microorganismos, necessitando desinfecção adequada após cada uso, evitando a contaminação cruzada e protegendo a equipe que o manuseia (Graziano et al., 2016). Recomenda-se que os aparelhos endoscópicos sejam submetidos à desinfecção de alto nível através de desinfetantes líquidos, por serem artigos semicríticos e termossensíveis (WGO, 2019). Esse processo reduz pelo menos 6-log das micobactérias e destruição de todos os outros microorganismos, exceto príons e esporos bacterianos (Oliveira \& Mati, 2015; Ribeiro et al., 2013), já as pinças de biópsia e cateter de esclerose devem ser esterilizados, pois rompem a mucosa do trato gastrointestinal (Rahman et al.,2019).

Atualmente, o reprocessamento dos acessórios e endoscópios flexíveis é de responsabilidade da enfermagem (Barbosa et al 2021). Para a Associação Brasileira de Enfermagem em Centro Cirúrgico, Recuperação Anestésica e Centro de Material e Esterilização (SOBECC) podem ocorrer erros de processamento devido a omissão ou inadequação na realização das etapas da limpeza, como falhas no processamento ou o transporte inadequado desses materiais, tornando desafiador o controle e a prevenção de infecções (Silva, 2011; Sobecc, 2017).

O reprocessamento de materiais médicos reutilizáveis ainda faz parte da realidade na área da saúde. Os princípios de gerenciamento de risco do tipo exposição-evento são difíceis de serem realizados no aprendizado clínico e os dados publicados não são conclusivos, o que torna o gerenciamento de risco imprescindível nesta prática (Costa ,2013) . O centro de endoscopia 
é um setor composto de várias áreas que destinam-se à realização de procedimentos endoscópicos e deve estar em condições para garantir a segurança dos pacientes e da equipe multiprofissional.

A adoção de protocolos institucionais tem se tornado uma prática frequente na área da saúde, os resultados de sua utilização têm demonstrado maior qualidade dos processos. É necessário que os profissionais que trabalham diretamente no processamento de endoscópios, sigam minuciosamente estas etapas. (Primo et al.,2020).

A área física deve estar de acordo com as normativas do Ministério da Saúde RDC no 6 de Março de 2013, essa área deve ser ampla o suficiente para que seja possível circular e trabalhar ao mesmo tempo, possibilitando a circulação do material dentro da sala, assim como a lavagem, a escovação, o enxágue e a desinfecção, seguida de destinação adequada a local próprio para secagem e armazenamento, sendo que estas etapas não se cruzam e ocorrem de forma sequencial (Brasil,2013).

Para o cumprimento da resolução, os serviços devem ser estruturados da seguinte forma: serviço de endoscopia tipo I - realiza-se procedimentos sem sedação, com ou sem anestésico tópico; serviço de endoscopia tipo II - além dos procedimentos descritos no tipo I, realiza-se procedimentos endoscópicos sob sedação consciente, com medicações que podem ser revertidas com uso de antagonistas; e serviço de endoscopia tipo III - que além dos procedimentos descritos nos tipos I e II, são realizados procedimentos endoscópicos sob qualquer tipo de sedação ou anestesia (Brasil,2013).

O objetivo deste estudo é relatar como realizamos o processo de limpeza e desinfecção dos endoscópios flexíveis num hospital escola no sul do Brasil.

\section{Metodologia}

Estudo descritivo, tipo relato de experiência, realizado por enfermeiras do serviço de endoscopia em 2021, abordando a limpeza e desinfecção dos endoscópios num hospital de grande porte, no sul do Brasil. Tem como cenário o setor de endoscopia, que está inserido no centro cirúrgico ambulatorial do hospital.

\section{Resultados}

O setor de endoscopia é composto por quatro salas que realizam aproximadamente 890 procedimentos endoscópicos ao mês, sendo estes: fibrobroncoscopia e endoscopia digestiva alta e baixa. Possui 41 aparelhos em uso, onde o número de reprocessamentos destes aparelhos varia de acordo com a quantidade de exames realizados, com média mensal de 890 reprocessamentos. O serviço funciona diariamente, sendo que à noite e em finais de semana são realizados apenas procedimentos em caráter de urgência.

A estrutura física abrange uma "área suja", destinada ao recebimento e limpeza dos endoscópios utilizados, que possui quatro cubas profundas para lavagem, duas pistolas de água e duas de ar comprimido. Na "área limpa", ocorre a desinfecção de alto nível automatizada, tendo duas pistolas de ar comprimido e cinco máquinas, sendo uma delas exclusiva para processar fibrobroncoscópios e as demais para realizar desinfecção em aparelhos de endoscopia digestiva alta e baixa. Cada área possui um funcionário responsável específico, e o fluxograma de processamento destes aparelhos segue etapas rígidas, com a finalidade de garantir a desinfecção destes equipamentos.

Ao término do exame é realizado uma pré-limpeza e teste de vazamento do aparelho endoscópico ainda na sala de exame. Com o aparelho conectado à torre de vídeo aspira-se água corrente da cuba com solução de detergente enzimático diluído. Após, o aparelho é desconectado da torre de vídeo, protegendo a parte elétrica com tampa. O transporte para a sala de desinfecção é realizado em contêiner identificado como material "sujo", acomodado e protegido, com a etiqueta de identificação do aparelho. Na área suja, realiza-se a limpeza manual do endoscópio, válvulas e acessórios, com auxílio de uma 
escova especial para limpeza dos canais de lúmen. O material orgânico é retirado com detergente enzimático, apropriado para a limpeza, conforme orientação do fabricante, seguido de enxágue e secagem com pistola de água e ar comprimido.

Durante a limpeza manual, observa-se a integridade do aparelho. Após, os aparelhos são passados por uma janela que interliga as áreas suja e limpa para a desinfecção de alto nível ser realizada. As lavadoras automatizadas são utilizadas para o reprocessamento dos endoscópios flexíveis, que são colocados e encaixados dentro da máquina. O equipamento ficará submerso primeiramente em detergente enzimático, sendo injetado em todos os canais e, após, na solução desinfetante (atualmente utilizamos ácido peracético) para desinfecção de alto nível. Em qualquer problema apresentado é emitido um sinal sonoro com interrupção do funcionamento e geração de relatório impresso. Ao término do processo, a máquina emite um sinal sonoro, imprime um comprovante que é analisado e arquivado. É realizada secagem manual com ar comprimido, embala-se o equipamento com capa de vídeolaparoscopia, mantendo a extremidade inferior aberta para ventilação, ficando acondicionado em armário próprio na posição vertical, devidamente identificado.

O detergente enzimático deve ser apropriado para a limpeza do material; utiliza-se escova de tamanho especial para limpeza dos canais de lúmen, enxaguando após a lavagem. Enquanto é realizada a limpeza manual, observa-se a integridade do aparelho para após ser encaminhado para a desinfecção de alto nível. O processo de limpeza de todos os canais, válvulas e conectores deve incluir escovação e irrigação de todos os componentes externos e internos com utilização de detergente, conforme orientação do fabricante. Após a limpeza, os aparelhos são passados por uma janela que interliga as áreas suja e limpa para ser realizada a desinfecção.

Coloca-se etiqueta no aparelho com a data do processamento, número da máquina onde foi reprocessado, lote do desinfetante, assinatura e carimbo do profissional responsável. Esta etiqueta será colada na folha de rastreabilidade no momento da realização do exame, ficando no prontuário do paciente para eventual consulta.

Semanalmente a enfermeira realiza, conforme orientação do controle de infecção hospitalar da instituição, cinco testes microbiológicos dos endoscópios em cada máquina, e um teste para cada endoscópio indicado escolhido de forma aleatória, totalizando seis aparelhos: dois de endoscopia digestiva alta, dois para colonoscopia e dois para fibrobroncoscopia. Diariamente é realizado o controle da concentração do ácido peracético com fita teste, onde se identifica a concentração do produto em cada máquina, que deve estar dentro dos critérios estabelecidos pelo fabricante. Registra-se em uma tabela de controle com a data e realização do teste como efetivo ou não efetivo. Caso o resultado seja não efetivo, o ácido peracético deve ser desprezado e preparada nova solução.

\section{Discussão}

\section{Ambiente Físico}

Todo processo de limpeza é descrito em protocolo a ser fidedignamente realizado pela equipe de enfermagem, conforme previsto nas exigências do Ministério da Saúde. O local destinado para limpeza deverá conter cuba para lavagem com profundidade suficiente que evite respingos nas laterais, no piso e no profissional, bancadas lisas e impermeáveis com dimensões compatíveis para acomodação dos equipamentos e acessórios, pontos de água com padrões de potabilidade, conforme normatização vigente e sistema de climatização (Brasil, 2012).

Serviços de endoscopia tipo I, que não utilizam no processamento produtos químicos para desinfecção de alto nível, devem possuir uma área para processamento de equipamentos, acessórios e outros produtos para a saúde com uma pequena diferença em relação ao ponto de água, atendendo os padrões de potabilidade. O sistema de climatização da sala de processamento deve garantir vazão mínima total de ar de $18,00 \mathrm{~m} 3 / \mathrm{h} / \mathrm{m}^{2}$. Também deve manter um diferencial de pressão negativa entre os ambientes adjacentes, com pressão diferencial mínima de 2,5 Pa, promovendo exaustão forçada de todo ar da sala com descarga para o exterior da edificação. O ar de reposição pode ser proveniente dos ambientes vizinhos (Brasil, 2012). 
Para o processo automatizado de limpeza, desinfecção e esterilização, a área física deve atender requisitos técnicos necessários para instalação do equipamento conforme indicação do fabricante e legislação vigente. Durante a secagem dos equipamentos com canais, o uso de ar comprimido medicinal, gás inerte ou ar filtrado, seco e isento de óleo é imprescindível ao serviço. Para atender a demanda, o serviço deverá manter à disposição equipamentos e acessórios em número suficiente para os procedimentos, respeitando o tempo hábil para o reprocessamento (Feitosa et al., 2020).

O serviço deve manter-se atualizado de acordo com a legislação vigente e manuais dos fabricantes, elaborando protocolos de limpeza através dos Procedimentos Operacionais Padrão (POP), aprovados pelo responsável técnico, estando disponível na sala de processamento para consulta pela equipe de saúde e pela autoridade sanitária competente (Oliveira et al., 2018).

\section{Limpeza dos Endoscópios}

A pré-limpeza do endoscópio deve ser realizada imediatamente após a finalização do procedimento com remoção da sujidade da superfície externa. Após, os endoscópicos e seus acessórios devem ser submetidos à secagem antes de qualquer método de desinfecção ou esterilização. Todo o material utilizado para a limpeza dos canais deve ser processado. O processo de desinfecção deve respeitar o tempo mínimo de exposição do equipamento ao produto utilizado. Um dos desinfetantes mais utilizados é o ácido peracético, ele tem algumas vantagens por ser biodegradável, atóxico e possuir ação efetiva em matéria orgânica, oxidando os componentes celulares (Nascimento et al., 2015). A monitorização dos parâmetros indicadores de efetividades dos agentes saneantes, que possuem ação antimicrobiana como concentração, pH ou outros indicados pelo fabricante, por pelo menos uma vez ao dia antes do início das atividades, é obrigatória. Os parâmetros monitorados - iniciais e subsequentes - devem ser registrados e arquivados pelo prazo mínimo de cinco anos e disponibilizados para consulta da autoridade sanitária (Sobecc, 2019).

Conforme a classificação de Spaulding, os instrumentos não críticos são aqueles que possuem contato somente com a pele, tendo baixo risco de infecção, requerendo desinfecção de baixo nível, ou limpeza simples com água e detergente. Os semi-críticos são os materiais que entram em contato com mucosas, apresentando risco moderado de infecção, devendo sofrer uma desinfecção de alto nível; a maioria dos endoscópios estão nesta categoria. Já os instrumentos críticos são aqueles que penetram no sistema vascular, tecidos e cavidades corporais, possuindo alto risco de infecção, devendo ser esterilizados (Rahman et al.,2019).

O processamento dos endoscópios desperta grande preocupação, pois a superfície interna e externa são expostas a um elevado número de microorganismos a partir do seu contato com o aparelho digestivo, o que enfatiza a necessidade de uma desinfecção adequada. Evidências sugerem que a transmissão de patógenos através dos aparelhos endoscópicos é um evento muito raro quando as diretrizes de reprocessamento são seguidas de forma correta (Mati et al.,2019).

Quando for necessário o transporte do endoscópio entre a sala de procedimento e a sala de processamento, estes devem estar acondicionados em recipientes laváveis e com tampas diferentes para material sujo e limpo. Dessa forma, assegura-se o transporte seguro do aparelho, diminuindo o risco de quedas e de contaminação por líquido e fluido do paciente, mantendo a segurança de todos (Brasil,2011). Sempre que o endoscópio for transportado para outra unidade, ele deve ser reprocessado novamente antes da sua utilização (Paczek et al.,2020).

Em razão disso, as diretrizes para reprocessamento de endoscópios flexíveis são ineficazes se não implementadas corretamente. Estudos constataram que a não conformidade com as diretrizes de reprocessamento pode ocasionar infecções relacionadas ao endoscópio (Kenters et al,2015). A vigilância microbiológica de endoscópios flexíveis é indicada para rastrear contaminações de endoscópios e prevenir infecções em pacientes após procedimentos (Kovaleva, 2016). É necessário que os profissionais que trabalham diretamente no processamento de endoscópios, sigam minuciosamente estas etapas (Gomes,2020). 
A prática correta de processamento de materiais traz segurança e qualidade aos materiais reprocessados, para isso, é necessário uma equipe responsável e capacitada (Silva et al.,2020). Neste contexto, estes estudos corroboram no compartilhamento de experiências dentro da unidade favorecendo o aprendizado de cada profissional.

Destaca-se como fator limitador deste estudo o fato de que foi realizado em um único serviço de endoscopia, limitando a experiência à realidade desse serviço.

\section{Conclusão}

O processo de limpeza e desinfecção dos endoscópios é desafiador, exige rotinas rigorosas e bem delineadas, norteando os profissionais a realizarem suas funções de forma a garantir a qualidade e a segurança na desinfecção destes aparelhos.

A realização do processo de desinfecção dos endoscópios leva à reflexão sobre como essa prática é realizada, envolvendo um maior número de pessoas, auxiliando para que um padrão seja estabelecido de maneira que todos os envolvidos possam entender a importância da estrutura física adequada e adesão correta da rotina, garantindo a desinfecção de alto nível dos aparelhos endoscópios, estabelecidas pelas normativas do Ministério da Saúde, para a segurança dos funcionários e pacientes.

\section{Referências}

Barbosa, M. C. T., Pinto, A. C. S., Alcantara, L. F. F. L., Macedo, E. C., Teixeira, V. M. F., Couto, L. L., et al. (2021). Helth Educacion through social media for patients undergoing digestive endoscopy: Integrative review. Research, Society and Development, 10(3), 4710312983. 10.33448/rsd-v10i3.12983.

Brasil. ANVISA. (2012). Resolução - RDC no 15, de 15 de março de 2012. Dispõe sobre requisitos de boas práticas para o processamento de produtos para saúde e dá outras providências. 2012. Disponível em: https://bvsms.saude.gov.br/bvs/saudelegis/anvisa/2012/rdc0015_15_03_2012.html.

Brasil. ANVISA (2013). Resolução- RDC nº 6, de 10 de março de 2013. Dispõe sobre os requisitos de Boas Práticas de Funcionamento para os serviços de endoscopia com via de acesso ao organismo por orifícios exclusivamente naturais. https://bvsms.saude.gov.br/bvs/saudelegis/anvisa/2013 /rdc0006_10_03_ 2013.html11

Feitosa, K.A., Ferraz, C. R. \& Feitosa, F. P. A. (2020). Compreensão da Equipe de Enfermagem de Uma Central de Material Frente ao Riscos Ocupacionais Relacionado ao Processo de Limpeza dos Artigos Médicos. Revista JRG de Estudos Acadêmicos, 3(7).

Gomes B. P., M., Guadagnin, S. V. T., Azevedo, A. da S., Costa L., C. da, Costa, D. de M., \& Ferreira Veiga Tipple, A. (2020). Experiência na implantação de um protocolo para processamento de endoscópios adotando uma metodologia ativa. Comunicação Em Ciências Da Saúde, 31(01), 189-196. $10.51723 /$ ccs.v31i01.622.

Graziano, K. U., Pereira, M. E. A. \& Koda, E. (2016). Proposta metodológica para a validação da eficácia de desinfecção de processadora automática de endoscópios flexíveis. Rev. Latino-Am. Enfermagem. 10.1590/1518-8345.0595.2745.

Kenters, N., Huijskens, E. G. W., Meier, C. \& Voss A.(2015). Infectious diseases linked to cross-contamination of flexible endoscopes. Endosc Int Open, 3:259-65. 10.1055/s-0034-1392099.

Kovaleva, J. Infectious complications in gastrointestinal endoscopy and their prevention. (2016). Best Pract Res Clin Gastroenterol., 30(5):689-704. 10.1016/j.bpg.2016.09.008.

Mati, M. L. M., Guimarães, N. R., Magalhães, P. P., Farias, L. M. \& Oliveira, A. C.(2019). Enzymatic detergent reuse in gastroscope processing: a potential source of microorganism transmission. Revista Latino-Americana de Enfermagem, 27, e3211. 10.1590/1518-8345.3101.3211.

Nascimento, A. C., Cunha, C. I. J., Silva, C. R. G., Leão, M. V. P., Santos, S. S. F. (2015). Estabilidade do ácido peracético no processo de desinfecção prévia à lavagem. Rev. Assoc. Paul. Cir. Dent, 69(.4). 367-382.

Oliveira, A.C. \& Mati, M. L. M. (2015). Fatores relacionados à troca das soluções de desinfecção dos aparelhos endoscópicos Rev. SOBECC, 20(1): 24-9. $10.5327 / Z 1414-4425201500010006$.

Oliveira, C. L., Silva, D. M. \& Bopsin, P. S.(2018). Desinfecção de endoscópios: revisão integrativa. Anais da XI Mostra Científica do CESUCA, 11:390-408. Disponível em: http://ojs.cesuca.edu.br/index.php/mostrac/article/view/1390.

Paczek, R. S., Espírito Santo, D. M. N. \& Galvan, C. (2020). Utilização de equipamentos de proteção individual em unidade endoscópica.Rev enferm UFPE on line. 2020;14:e243993. 10.5205/1981-8963.2020.243993.

Primo, M. G. B., Guadagnin, S. V. T., Azevedo, A. S., Luciano, C. C., Costa, D. M., \& Tipple, A. F. V. (2020). Experiência na implantação de um protocolo para processamento de endoscópios adotando uma metodologia ativa. Comunicação Em Ciências Da Saúde, 31(01), 189-196. 10.51723/ccs.v31i01.622. 
Research, Society and Development, v. 10, n. 8, e6810817126, 2021

(CC BY 4.0) | ISSN 2525-3409 | DOI: http://dx.doi.org/10.33448/rsd-v10i8.17126

Rahman, M. R., Perisetti, A., Coman, R. M., Bansal, P., Chhabra, R. \& Goyalet, H. (2019). Duodenoscope-Associated Infections: Update on an Emerging Problem. Dig Dis Sci, 64: 1409-18. 10.1007/s10620-018-5431-7.

Ribeiro, M. M., Oliveira, A. C., Ribeiro, S. M., Watanabe, E., Stoianoff, M. A. R. \& Ferreira, J. A.(2013). Eficácia do reprocessamento de endoscópio gastrointestinal flexível. Infect Control Hosp Epidemiol, 34 (3): 309 - 12. 10.1086/669518.

Sobecc (2017). Diretrizes de Práticas em Enfermagem Cirúrgica e Processamento de Produtos para a Saúde. Rev. SOBECC. (7a ed.), Manole:135-46.

Schwab, K. \& Singh, S. (2011). An introduction to flexible endoscopy. Surgery, 29 (2): 80-4. 10.1016/j.mpsur.2010.11.014.

Silva, J. M. B., Loureiro, L. H., Silva, I. C. M. \& Novaes, M. L. (2020). Coronavirus and the disinfection and reprocessing protocols of hospital articles. Research, Society and Development, 9(9), e29996187. 10.33448/rsd-v9i9.6187.

WGO. World Gastroenterology Organization (2019). Endoscope disinfection update: a guide to resource-sensitive reprocessing. USA: World Gastroenterology Organization. Disponível em: https://www.worldgastroenterology.org/UserFiles/file/guidelines/endoscope-disinfection-english-2019.pdf. 